\title{
Smart Home Energy Management
}

\author{
Giovanni Pau ${ }^{1, *}$, Mario Collotta ${ }^{1}$, Antonio Ruano ${ }^{2,3}$ and Jiahu Qin ${ }^{4}$ \\ 1 Computers Engineering and Networks Laboratory, Faculty of Engineering and Architecture, \\ Kore University of Enna, Cittadella Universitaria, Enna 94100, Italy; mario.collotta@unikore.it \\ 2 Faculty of Science and Technology, University of Algarve, Campus de Gambelas, 8005-139 Faro, Portugal; \\ aruano@ualg.pt \\ 3 IDMEC, Instituto Superior Técnico, Universidade de Lisboa, 1049-001 Lisboa, Portugal \\ 4 Department of Automation, University of Science and Technology of China, Hefei 230027, China; \\ jhqin@ustc.edu.cn \\ * Correspondence: giovanni.pau@unikore.it; Tel.: +39-0935-536494
}

Academic Editor: Enrico Sciubba

Received: 15 March 2017; Accepted: 16 March 2017; Published: 17 March 2017

\section{Introduction}

The new challenges on Information and Communication Technologies (ICT) in Automatic Home Systems (AHS) focus on the methods useful to monitor, control, and optimize the data management flow and the use of energy. An AHS is a residential dwelling, in some cases with a garden or an outdoor space, equipped with sensors and actuators to collect data and send controls according to the activities and expectations of the occupants/users. Home automation provides a centralized or distributed control of electrical appliances. Adding intelligence to the home environment, it would be possible to obtain, not only excellent levels of comfort, but also energy savings both inside and outside the dwelling, for instance using smart solutions for the management of the external lights and of the garden.

Several approaches have been studied in the last years such as advanced metering infrastructure (AMI) [1], smart sensor technologies [2], smart home appliances [3], home area network (HAN) [4] and home energy storage system (HESS) [5]. In general, a Smart Home Energy Management (SHEM) refers to the application of supervisory control and data acquisition with energy management systems, including the generation, the transmission and distribution systems of the electrical network, namely with the concept of the smart grid. This concept has been widely accepted in order to suggest the future development trend of power grids.

In this direction, SHEM has become essential for residential customers, such as the home system, for the successful demand-side management of smart grids [6]. SHEM deals with the real-time monitoring and arranging of various home appliances, based on user's preferences via intelligent ambient systems controlled by a human-machine interface in smart houses, with the aim of electricity cost reduction and energy utilization efficiency improvements [7].

SHEM has been developed also to monitor home renewable energies (wind turbines, solar panels, etc.) due to the growing concerns on global energy security and environmental emissions. Coupled with the rapid development in advanced power electronics and renewable energy technologies, some intelligent systems could be incorporated in SHEM to make the best use of the stored energy sources installed at the residential buildings: it would lead the improvement of indoor home efficiency of energy conversion and utilization [8]. Finally, SHEM is an important challenge to achieving demand response, demand side management, peak shaving and the load shifting which are addressed with the aim to offer solutions to the customer or network operators [9].

For these reasons, in recent years, SHEM has attracted more interest from the research community. The main reason is that the use of modern automation technology in the home promises considerable 
savings of energy, therefore, simultaneously reducing the operational costs of the building over its whole lifecycle. However, the full potential of smart homes still lies fallow, due to the complexity and diversity of the systems, as well as the frequent problem of suboptimal control strategies. As a consequence, the energy consumption is still higher than actually necessary and users are unable to yield full comfort in their automated homes. Considering the rapid development of this field in recent years, several solutions and approaches are thus still needed in order to address the requirements imposed by the smart home energy management systems, through the development of smart solutions, intelligent algorithms, and novel network paradigms.

The goal of this Special Issue was to bring together a wide range of disciplines and technical fields to solve open problems and challenges typical of smart home energy management systems, efficiently integrating novel solutions, and focusing on performance evaluations and comparisons with existing standards. In the next section, we provide a brief review of the papers published, roughly classifying them according to thematic areas.

\section{A Review of the Contributions in This Special Issue}

Several papers can be grouped under the broad heading of Energy Management. In fact, a home energy management system is the core of optimal operation for a smart home, representing an important component of the smart grid on the user side.

Fan et al. [10] propose an online event-triggering algorithm for energy management of smart households in order to reduce the electricity cost, with a guarantee of comfort level for household members. The proposed energy management solution can deal with the random demand of consumers and is implemented without user intervention. As a consequence, household members do not need to manually preset the operation time interval of appliances. A Lyapunov optimization method is adopted in order to schedule the controllable load in the household based only on the current information. Moreover, with the aim to trigger the execution of the online algorithm, so as to cut down the execution frequency and unnecessary calculation, an event-triggered mechanism is used by the authors. Simulation results show that the proposed solution could effectively decrease the electricity bill and guarantee the comfort level of users.

A theoretical coalitional game approach, for the cooperation between households and load serving entity in a smart community, is presented by Fan et al. in [11]. The authors, considering the potential demand response ability of air conditioning units, aim to use them in order to decrease the energy costs of a smart community. The proposed air conditioning controller is designed to reduce the amount of electricity purchased from the main grid by controlling air conditioning units. This is made possible by an online air conditioning energy management algorithm, based on Lyapunov optimization, that considers both the air conditioning energy consumption and the thermal comfort level of consumers. The obtained results demonstrate that the proposed coalitional game has significant potential to serve as an effective means of improving the profitability of the load-serving entity and cutting the expenses of householders.

Ikpehai et al. [12] present an empirical assessment of low-power Power Line Communication (PLC) system over the IPv6 network (called 6LoPLC) for a home energy management systems. A model is developed in the NS-3 simulator and the network performance is validated with several measurements. The obtained results provide some useful insights for system designers and application developers. Furthermore, the model presented in this paper is also feasible for smart grid applications and other cyber-physical systems, where high reliability and low cost are of higher priority than high throughput.

Ahmed et al. [13] show the application of a lightning search algorithm in order to solve the problems of Artificial Neural Network (ANN) of finding the optimum rate and the best value of neurons that can be used in a home energy management scheduling controller. In fact, it is known that demand response program can shift peak time load to off-peak time, thereby reducing greenhouse gas emissions and allowing energy conservation. For this reason, the home energy management scheduling controller of the residential response program strategy, proposed by the authors, aims to predict the 
optimal ON/OFF status of home appliances. The obtained results show that the solution proposed by the authors achieve a better response in switching the status in the home energy management scheduling controller, allowing a substantial energy saving.

The aim of Nguyen et al. [14] is to investigate how consumer behavior changes after the application of dynamic electricity pricing and the persistence of those changes. They carry out a deep investigation focused in this research field and also discuss the policy implications of demand management to shift consumption to days that have more solar radiation, while at the same time reducing overall consumption. To this end, a dynamic pricing experiment is implemented on Nushima Island, located in the center of Japan, with the participation of 50 households. The results show that dynamic pricing brought about $13.8 \%$ reduction of electric energy consumption in comparison with the pre-experiment period. These results can be useful to develop a policy for sustainable energy conservation in remote islands.

Moon et al. [15] have developed an ANN prediction model for controlling building heating systems. The main aim is to obtain the ascent time of indoor temperature from the setback period (when a building is not occupied) to a target setpoint temperature (when a building is occupied). The obtained value is applied in order to determine the proper moment to start increasing the temperature from the setback temperature to reach the target temperature at an appropriate time. The performance of the proposed ANN is widely validated and the obtained results are promising.

A smart meter is an essential tool for successful balancing the demand-offer energy curve. It allows the linking of the consumption and production measurements with the time information and the customer's identity, enabling the substitution of flat-price billing with smarter solutions, such as Time-of-Use or Real-Time Pricing. In this research field, Pitì et al. [16] review the ongoing situation in Europe regarding real-time services for the final customers. Moreover, they analyze the architectural and technological options that have been considered for the roll-out phase of the Italian second generation of smart meters.

A new multi-user full-duplex Visible Light Communication (VLC) system to be used in a smart home environment is introduced by Niaz et al. [17]. The proposed system is capable of accommodating data for both users and smart devices on downlink while also providing uplink connectivity. The authors take into account both the performance of the proposed system and, mainly, the cost and the power consumption. Simulation results show that the solution introduced by the authors met the requirements of data transmission in an indoor environment such as a smart home. Furthermore, as far as the cost and power consumption, the authors highlight that the initial cost of the proposed VLC system is high but when compared to the running cost, which includes the power consumption and maintenance costs, the proposed VLC system turned out to be a more cost-effective solution.

The goal of maintaining users' thermal comfort conditions in indoor environments may require complex regulation procedures and a proper energy management. For this reason, Alamin et al. [18] present an economic model-based predictive control (MPC) whose main strength is the use of the day-ahead price (DAP) in order to predict the energy consumption associated with the heating, ventilation and air conditioning (HVAC). In this way, the control system is able to maintain a high thermal comfort level by optimizing the use of the HVAC system and to reduce, at the same time, the energy consumption associated with it, as much as possible. The obtained results show that the control system introduced by the authors are able to achieve a tradeoff between users' thermal comfort and the amount of energy spent to reach this thermal comfort. As a result, the proposed control strategy is able to manage the energy spent through the use of the DAP, whereas the users' thermal comfort is maximized.

\section{Conclusions}

This Special Issue highlights the fact that smart homes continue to attract a lot of interest from the research community. The main reason is that the use of modern automation technology in home 
scenarios promises considerable savings of energy, therefore, simultaneously reducing the operational costs of the building over its whole lifecycle. However, the full potential of smart homes still lies fallow, due to the complexity and diversity of the systems, as well as the frequent problem of suboptimal control strategies. As a consequence, energy consumption is still higher than actually necessary and users are unable to yield full comfort in their automated homes. To cope with this problem, several papers were included in this Special Issue, presenting new solutions and approaches in order to address the requirements imposed by the smart home energy management systems. The accepted papers introduce smart solutions, intelligent algorithms and novel network paradigms that provide a concrete contribution to the literature that deals with the smart home energy management.

Acknowledgments: The authors are grateful to the MDPI Publisher for the invitation to act as guest editors of this special issue and want to thank the editorial staff of Energies for the kind co-operation, patience and committed engagement.

Author Contributions: The authors contributed equally to this work.

Conflicts of Interest: The authors declare no conflict of interest.

\section{References}

1. Ikpehai, A.; Adebisi, B.; Rabie, K.M. Broadband PLC for Clustered Advanced Metering Infrastructure (AMI) Architecture. Energies 2016, 9, 569. [CrossRef]

2. Ahmed, M.A.; Kang, Y.C.; Kim, Y.-C. Communication Network Architectures for Smart-House with Renewable Energy Resources. Energies 2015, 8, 8716-8735. [CrossRef]

3. Bradac, Z.; Kaczmarczyk, V.; Fiedler, P. Optimal Scheduling of Domestic Appliances via MILP. Energies 2015, 8, 217-232. [CrossRef]

4. Collotta, M.; Pau, G. A Novel Energy Management Approach for Smart Homes Using Bluetooth Low Energy. IEEE J. Sel. Areas Commun. 2015, 33, 2988-2996. [CrossRef]

5. Pascual, J.; Sanchis, P.; Marroyo, L. Implementation and Control of a Residential Electrothermal Microgrid Based on Renewable Energies, a Hybrid Storage System and Demand Side Management. Energies 2014, 7, 210-237. [CrossRef]

6. Collotta, M.; Pau, G. A Solution Based on Bluetooth Low Energy for Smart Home Energy Management. Energies 2015, 8, 11916-11938. [CrossRef]

7. Collotta, M.; Pau, G. An Innovative Approach for forecasting of Energy Requirements to improve a Smart Home Management System based on BLE. IEEE Trans. Green Commun. Netw. 2017. [CrossRef]

8. Subbiah, R.; Pal, A.; Nordberg, E.K.; Marathe, A.; Marathe, M.V. Energy Demand Model for Residential Sector: A First Principles Approach. IEEE Trans. Sustain. Energy 2017. [CrossRef]

9. Javaid, N.; Javaid, S.; Abdul, W.; Ahmed, I.; Almogren, A.; Alamri, A.; Niaz, I.A. A Hybrid Genetic Wind Driven Heuristic Optimization Algorithm for Demand Side Management in Smart Grid. Energies 2017, 10, 319. [CrossRef]

10. Fan, W.; Liu, N.; Zhang, J. An Event-Triggered Online Energy Management Algorithm of Smart Home: Lyapunov Optimization Approach. Energies 2016, 9, 381. [CrossRef]

11. Fan, W.; Liu, N.; Zhang, J.; Lei, J. Online Air-Conditioning Energy Management under Coalitional Game Framework in Smart Community. Energies 2016, 9, 689. [CrossRef]

12. Ikpehai, A.; Adebisi, B.; Rabie, K.M.; Haggar, R.; Baker, M. Experimental Study of 6LoPLC for Home Energy Management Systems. Energies 2016, 9, 1046. [CrossRef]

13. Ahmed, M.S.; Mohamed, A.; Homod, R.Z.; Shareef, H. Hybrid LSA-ANN Based Home Energy Management Scheduling Controller for Residential Demand Response Strategy. Energies 2016, 9, 716. [CrossRef]

14. Nguyen, T.T.K.; Shimada, K.; Ochi, Y.; Matsumoto, T.; Matsugi, H.; Awata, T. An Experimental Study of the Impact of Dynamic Electricity Pricing on Consumer Behavior: An Analysis for a Remote Island in Japan. Energies 2016, 9, 1093. [CrossRef]

15. Moon, J.W.; Chung, M.H.; Song, H.; Lee, S.-Y. Performance of a Predictive Model for Calculating Ascent Time to a Target Temperature. Energies 2016, 9, 1090. [CrossRef]

16. Pitì, A.; Verticale, G.; Rottondi, C.; Capone, A.; Lo Schiavo, L. The Role of Smart Meters in Enabling Real-Time Energy Services for Households: The Italian Case. Energies 2017, 10, 199. [CrossRef] 
17. Niaz, M.T.; Imdad, F.; Kim, H.S. Power Consumption Efficiency Evaluation of Multi-User Full-Duplex Visible Light Communication Systems for Smart Home Technologies. Energies 2017, 10, 254. [CrossRef]

18. Alamin, Y.I.; Castilla, M.M.; Álvarez, J.D.; Ruano, A. An Economic Model-Based Predictive Control to Manage the Users' Thermal Comfort in a Building. Energies 2017, 10, 321. [CrossRef]

(c) 2017 by the authors. Licensee MDPI, Basel, Switzerland. This article is an open access article distributed under the terms and conditions of the Creative Commons Attribution (CC BY) license (http://creativecommons.org/licenses/by/4.0/). 